\title{
Chemical composition, antioxidant potential and antimicrobial activities of Ixora scheffleri subspecies keniensis essential oil
}

\begin{tabular}{|c|c|}
\hline \multicolumn{2}{|c|}{$\begin{array}{l}\text { Authors: } \\
\text { Peter K. Njenga } 1 \text { (1) } \\
\text { Samuel M. Mugo }{ }^{2} \text { (1) }\end{array}$} \\
\hline \multicolumn{2}{|c|}{$\begin{array}{l}\text { Affiliations: } \\
\text { 'Department of Botany, } \\
\text { Jomo Kenyatta University of } \\
\text { Agriculture and Technology } \\
\text { (JKUAT), Thika, Kenya }\end{array}$} \\
\hline \multicolumn{2}{|c|}{$\begin{array}{l}{ }^{2} \text { Department of Physical } \\
\text { Sciences-Chemistry, Grant } \\
\text { MacEwan University, } \\
\text { Edmonton, Canada }\end{array}$} \\
\hline \multicolumn{2}{|c|}{$\begin{array}{l}\text { Corresponding author: } \\
\text { Peter Njenga, } \\
\text { pknjenga@jkuat.ac.ke }\end{array}$} \\
\hline \multicolumn{2}{|c|}{$\begin{array}{l}\text { Dates: } \\
\text { Received: } 23 \text { Mar. } 2018 \\
\text { Accepted: } 12 \text { Aug. } 2019 \\
\text { Published: } 13 \text { Feb. } 2020\end{array}$} \\
\hline \multicolumn{2}{|c|}{$\begin{array}{l}\text { How to cite this article: } \\
\text { Njenga, P.K. \& Mugo, S.M., } \\
\text { 2020, 'Chemical composition, } \\
\text { antioxidant potential and } \\
\text { antimicrobial activities of } \\
\text { Ixora scheffleri subspecies } \\
\text { keniensis essential oil', } \\
\text { Journal of Medicinal Plants } \\
\text { for Economic Development } \\
\text { 4(1), a58. https://doi.org/ } \\
\text { 10.4102/jomped.v4i1.58 }\end{array}$} \\
\hline \multicolumn{2}{|c|}{$\begin{array}{l}\text { Copyright: } \\
\text { ( 2020. The Authors. } \\
\text { Licensee: AOSIS. This work } \\
\text { is licensed under the } \\
\text { Creative Commons } \\
\text { Attribution License. }\end{array}$} \\
\hline \multicolumn{2}{|l|}{ Read online: } \\
\hline 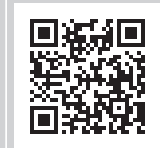 & $\begin{array}{l}\text { Scan this QR } \\
\text { code with your } \\
\text { smart phone or } \\
\text { mobile device } \\
\text { to read online. }\end{array}$ \\
\hline
\end{tabular}

Background: Essential oil (EO) obtained from Ixora scheffleri subspecies (subsp.) keniensis has valuable biological properties and can play a possible therapeutic role because of its antimicrobial and antioxidant nature.

Aim: In this article, the chemical constituents, antimicrobial activity and antioxidant capacity of the EO obtained from Ixora scheffleri subsp. keniensis were determined using standard procedures.

Setting: Plant material collection, essential oils extractions and antimicrobial assays were performed at Jomo Kenyatta University of Agriculture and Technology (JKUAT), Department of Botany Laboratories. Gas Chromatography Mass Spectrophotometry (GC/MS) analysis was carried out at the Physical Science Laboratory, MacEwan University, Canada.

Methods: The chemical constituents were determined using GC/MS. The total phenol content was evaluated using the Folin-Ciocalteu procedure. The antioxidant activity was determined using 2,2-diphenyl-1- picrylhydrazyl (DPPH) and $\beta$-carotene linoleic acid assays. The antimicrobial assay was performed using the disc diffusion method.

Results: The total phenol content of the EO was estimated to be $91.6 \mu \mathrm{g} / \mathrm{mg} \pm 0.5 \mu \mathrm{g} / \mathrm{mg}$. The antioxidant activity of EO obtained from Ixora relative to ascorbic acid was found to be $52 \%$ using the $\beta$-carotene linoleic acid assay. The DPPH scavenging activity of $30 \mu \mathrm{g} / \mathrm{mL}$ EO obtained from Ixora and $30 \mu \mathrm{g} / \mathrm{mL}$ ascorbic acid was $81.65 \%$ and $97.0 \%$, respectively. The EO was found to have significant susceptibility against Escherichia coli, and intermediate susceptibility against Candida albicans. However, Staphylococcus aureus, Bacillus subtilis and Pseudomonas aeruginosa showed complete resistance.

Conclusion: The in vitro chemical compositional analysis of EO obtained from Ixora scheffleri subsp. keniensis confirms the presence of phenolic compounds attesting to the antioxidant properties and antimicrobial properties.

Keywords: Ixora scheffleri; essential oils; phenolic compounds; antioxidant; antimicrobial.

\section{Introduction}

Ethnopharmacological surveys show that there has been a tremendous demand for the use of indigenous medicinal plant extracts as health enhancers and herbal therapies. Essential oils (EOs) obtained from plant extracts contain chemical compounds, such as vitamins, flavonoids, polyphenols, flavones, isoflavones, flavonoids anthocyanin, coumarin lignans, catechins and isocatechins, which are believed to have useful antioxidant and therapeutic properties (Antolovich et al. 2000; Mollica et al. 2016). Antioxidants are unique compounds having the ability to trap highly reactive free radicals and reactive oxygen species (ROS). These free radicals and ROS may oxidise nucleic acids, proteins, lipids or deoxyribonucleic acid (DNA) and can initiate degenerative diseases such as atherosclerosis, stroke, diabetes, Alzheimers, and cancer in humans (Ushio-Fukai \& Nakamura 2008). Antioxidants are believed to be prophylactic for the mentioned diseases. Living cells possess an inherent ROS scavenging mechanism, but this becomes inefficient with age and under environmental stresses; hence, dietary supplementation with synthetic antioxidants is necessary (Barros et al. 2011). There are, however, toxicological and mutagenic concerns related to synthetic antioxidants such as butylated hydroxytoluene (BHT) and butylated hydroxyanisole (BHA) commonly used in foods and this has exacerbated the need to source and screen for naturally occurring antioxidants (Amiri 2014; Gholivand et al. 2010; Peschel et al. 2006). 
Several methodologies have been used to monitor and compare the antioxidant activity of foods, natural and synthetic compounds and extracts of various natural sources including medicinal herbs (Antolovich et al. 2002; Politeo, Jukic \& Milos 2006; Terpinc, Bezjak \& Abramovic 2009; Topal et al. 2016). All these various methods used to measure antioxidant activity can give varying results depending on the specificity of the free radical being used as a reactant and as such it is ideal to use a number of methods in combination for more representative and comparative outcomes.

Herbal drugs made from medicinal plants have been used from ancient times to treat various diseases and their antimicrobial properties make them a rich source of many potent drugs (Srivastava, Lambert \& Vietmeyer 2005). Plants with medicinal value produce phytochemicals that have antimicrobial activity. In the last few decades, many bacterial organisms have continued to show increasing resistance to current antimicrobial agents (Nascimento et al. 2000). Therefore, more plant extracts need to be screened for useful antimicrobial components of therapeutic value. Currently, there is very little information available on this aspect for the Ixora scheffleri subspecies (subsp.) keniensis EO extract. The selected bacterial pathogenic members used for this study are associated with various infections in humans while Candida albicans is a yeast fungus that can cause systemic infections in immune-compromised individuals.

Ixora, belonging to the family Rubiaceae, is a large rain forest genus comprising shrubs and small trees. Estimates of species number range between 300 and 400 (Bridson 1988). Two sub species of I. scheffleri have been identified: I. scheffleri subsp. keniensis and I. scheffleri subsp. scheffleri. I. scheffleri subsp. keniensis is a small tree (Figure 1), up to $8 \mathrm{~m}$ tall with opposite long narrow leaves. Flowers are whitish-pink with a long corolla tube. The I. scheffleri subsp. keniensis plant (called

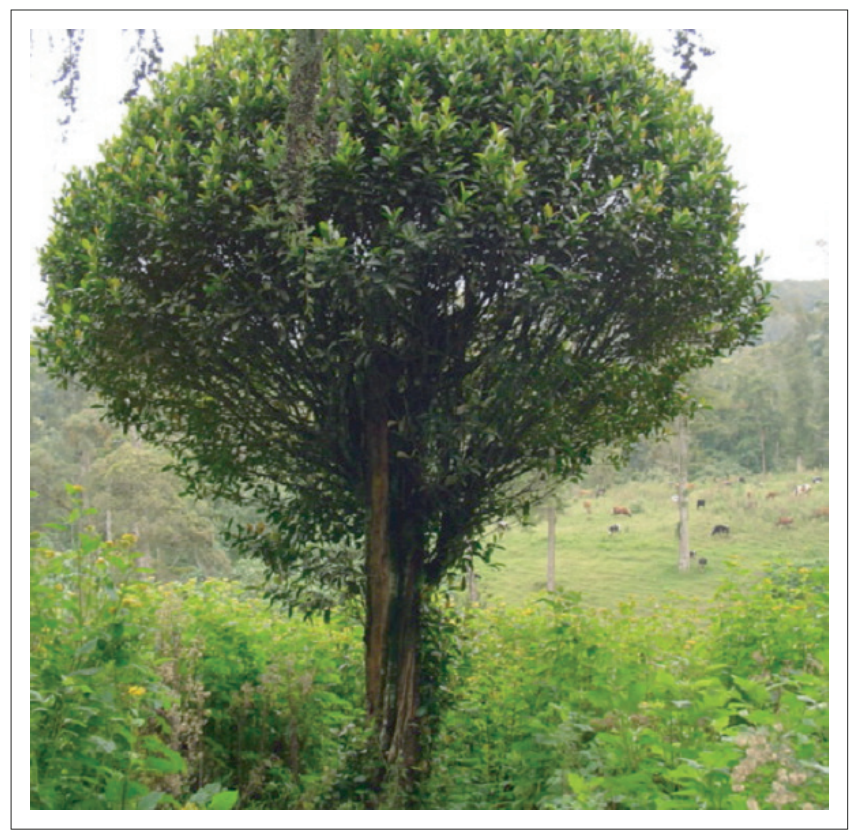

Source: Photo taken by author Peter K. Njenga.

FIGURE 1: The Ixora scheffleri subspecies keniensis plant. mutichuma or Muthioya (kikuyu) is rare, vulnerable and endangered (Beentje, Adamson \& Bhanderi 1994; Bridson 1988). The reason for this status is that logging has seriously depleted the camphor forests within the Mt Kenya forest reserve, Kenya to which the plant is endemic. This tree has very dense wood which produces a special charcoal for smelting (Gachathi 2007). Its designation in the Red list category and criteria is CR B1 + 2 (International Union for Conservation of Nature [IUCN] 2004). A group of botanists from Jomo Kenyatta University of Agriculture and Technology (JKUAT) discovered about 17 plants in 1999 in the Mt Kenya region and embarked on successful tissue culture studies of this species. The botanists have been able to reintroduce the plant in a number of areas in Kenya and are actively involved in its cultivation and conservation.

The aim of this study was to evaluate the chemical composition, antimicrobial activities and antioxidant properties of EO from the leaves of I. scheffleri subsp. keniensis.

\section{Materials and methods Materials}

\section{Plant material}

Leaves were gathered from I. scheffleri subsp. keniensis originally planted for the study in the botanical garden of JKUAT, Thika Central Kenya. A voucher specimen number 3000 has been deposited at the herbarium at JKUAT's Department of Botany for future reference.

\section{Solvents and chemicals}

Methanol (American Chemical Society [ACS] grade), chloroform (ACS grade), linoleic acid, ascorbic acid, $\beta$-carotene, 2,2-diphenyl-1-picrylhydrazyl (DPPH, 95\%), dimethyl sulphoxide (DMSO), anhydrous sodium sulphate, sodium carbonate, Folin-Ciocalteu reagent, gallic acid, Tween 40, deionised water (DI) and Whatman filter paper no. 3, 6-mm diameter were purchased from Sigma-Aldrich, Oakville, Ontario, Canada. The microbes including, Staphylococcus aureus (ATCC 25923), Bacillus subtilis (ATCC 6633), Escherichia coli (ATCC 25922), Pseudomonas aeruginosa (ATCC 2785), C. albicans (ATCC 90028) were all obtained from the Department of Botany at JKUAT, Juja, Kenya.

\section{Extraction of essential oil}

Fifty grams of I. scheffleri subsp. keniensis leaves were pulverised and then steam distilled for 6 hours using a Clevenger-type apparatus as recommended by British pharmacopoeia, 1988 to yield $0.77 \%$ weight/volume $(\mathrm{w} / \mathrm{v})$ waxy EO. The obtained EO was dried over anhydrous sodium sulphate and then stored in sealed vials at $+4{ }^{\circ} \mathrm{C}$ prior to chemical composition and antimicrobial activity analysis. For antioxidant determination assays, stock solutions of samples were prepared by dissolving $50 \mathrm{mg}$ of the EO extract in $25 \mathrm{~mL}$ of respective solvents, to obtain a final concentration of $2 \mu \mathrm{g} / \mu \mathrm{L}$. From this stock solution, different volumes of samples were taken for various 
experiments. The antimicrobial activity stock sample was prepared in a concentration of $100 \mathrm{mg} / \mathrm{mL}$ in DMSO.

\section{Gas chromatography mass spectrometry analysis}

Gas chromatography mass spectrometry analyses were performed on an Agilent capillary gas chromatograph directly coupled to the mass spectrometer system (model GC). A HP5MS non-polar fused silica capillary column $(60 \mathrm{~m} \times 0.25 \mathrm{~mm}$, $0.5 \mu \mathrm{m}$ film thickness) was used under the following conditions: oven temperature programmed from $50{ }^{\circ} \mathrm{C}$ (6 minutes) to $250{ }^{\circ} \mathrm{C}$ at $3{ }^{\circ} \mathrm{C} / \mathrm{min}$ and the final temperature retained for $20 \mathrm{~min}$; injector temperature, $250{ }^{\circ} \mathrm{C}$; helium carrier gas, flow rate $10 \mathrm{~mL} / \mathrm{min}$; the volume of the injected sample was $1 \mu \mathrm{L}$ of oil diluted in hexane; splitless injection technique; ionisation energy $70 \mathrm{eV}$, in the electronic ionisation mode; ion-source temperature $200{ }^{\circ} \mathrm{C}$; a scan mass range of mass-to-charge ratio $(\mathrm{m} / \mathrm{z}) 30-450$ and interface temperature $300{ }^{\circ} \mathrm{C}$. The constituents of EOs were identified based on their Kovats index, calculated in relation to the retention times of a series of linear alkanes (C4-C28), in comparison with Kovats index values of reference products of the appropriate chemical components gathered based on the Adams table (Derwich et al. 2009; Politeo et al. 2006; Vemin, Lageot \& Parkanyi 1998). Identification was also realised by comparing their mass spectra with those gathered in a library of National Institute of Standards and Technology (NIST)-Mass Spectrum (MS) type and with those reported in the literature.

\section{Antioxidant activity}

\section{2,2-diphenyl-1-picrylhydrazyl assay}

The DPPH colorimetric assay was conducted as described in literature (Akowuah et al. 2005; Okoh, Sadimenko \& Afolayan 2011; Terpinc et al. 2009) to test the ability of I. scheffleri subsp. keniensis EOs to act as free radical scavengers or hydrogen donors. Briefly, $1.7 \mathrm{~mL}$ of $0.5 \mathrm{mM}$ DPPH solution in methanol was added to a set of six vials of different concentrations $(0 \mu \mathrm{g} / \mathrm{mL}, 10 \mu \mathrm{g} / \mathrm{mL}, 20 \mu \mathrm{g} / \mathrm{mL}, 30 \mu \mathrm{g} / \mathrm{mL}, 40 \mu \mathrm{g} / \mathrm{mL}, 50 \mu \mathrm{g} /$ $\mathrm{mL}, 60 \mu \mathrm{g} / \mathrm{mL}, 70 \mu \mathrm{g} / \mathrm{mL}$ and $80 \mu \mathrm{g} / \mathrm{mL}$ ) of EO obtained from I. scheffleri subsp. keniensis prepared using methanol as a solvent. The mixtures were thoroughly mixed and left in the dark at room temperature for $60 \mathrm{~min}$. The absorbance of each solution was measured at 517 nanometer (nm) using a PerkinElmer Lambda 45 spectrophotometer. The procedure was repeated with the same varying concentrations of ascorbic acid $(0 \mu \mathrm{g} / \mathrm{mL}-80 \mu \mathrm{g} / \mathrm{mL})$ in methanol as a reference antioxidant standard. Each sample was measured in triplicate and averaged. The free radical scavenging activity (FRSA \%) was calculated using the formula:

FRSA $\%=\left[\left(\frac{A_{\text {blank }}-A_{\text {sample }}}{A_{\text {blank }}}\right) \times 100\right]$

[Eqn 1]

where $A_{\text {blank }}$ is the absorbance of the control reaction (containing all reagents except the test compound) and $A_{\text {sample }}$ is the absorbance of the test compound (Hatano et al. 1988). The sample concentration required to reduce the absorbance of DPPH by $50 \%\left(\mathrm{IC}_{50}\right)$ was determined by plotting inhibition percentages against the concentration of the sample. A lower $\mathrm{IC}_{50}$ value indicates a greater antioxidant potency.

\section{6-carotene linoleic acid assay}

Briefly, $500 \mu \mathrm{L}$ of $\beta$-carotene solution $(1 \mathrm{mg} / \mathrm{mL}$ in chloroform), $1 \mathrm{~mL}$ of linoleic acid solution $(10 \mathrm{mg} / \mathrm{mL}$ in chloroform) and $333 \mu \mathrm{L}$ of Tween 40 solution $(300 \mathrm{mg} /$ $\mathrm{mL}$ in chloroform) were combined in a $100 \mathrm{~mL}$ flask with vigorous shaking. The chloroform was removed by rotary evaporation at $40{ }^{\circ} \mathrm{C}$ for $5 \mathrm{~min}$. Fifty millilitres of deionized (DI) was added to the residue and mixed thoroughly to create an emulsion. Fifty grams of I. scheffleri subsp. keniensis EO samples were dissolved in $25 \mathrm{~mL}$ DMSO to obtain a final concentration of $2 \mu \mathrm{g} / \mu \mathrm{L}$, and a $350-\mu \mathrm{L}$ aliquot of the solution was added to $2.5 \mathrm{~mL}$ of the aboveprepared reagent mixture and mixed thoroughly. The absorbance was immediately measured at $490 \mathrm{~nm}$ against a blank, consisting of an emulsion without $\beta$-carotene. The tubes were incubated for $2 \mathrm{~h}$ at $50{ }^{\circ} \mathrm{C}$ incubation and the absorbance was noted at $490 \mathrm{~nm}$. The procedure was repeated with BHT as a positive control and a $350-\mu \mathrm{L}$ methanol blank was prepared for background correction. Tests were carried out in triplicate. Relative antioxidant activities (RAA\%) activity was calculated by dividing the absorbency of the sample by the absorbency of butylated hydroxytoluene (BHT) using the following equation:

$\%$ Antioxidant activity $=(\beta$-carotene content after $2 \mathrm{~h}$ of assay/initial beta-carotene content) $\times 100$

[Eqn 2]

\section{Determining the total phenol content}

Total phenol content was measured using the FolinCiocalteu colorimetric procedure described previously (Taga, Miller \& Pratt 1984), which determines how much of the test sample is necessary to repress the oxidation of the Folin-Ciocalteu reagent. A $50-\mu \mathrm{L}(2 \mu \mathrm{g} / \mu \mathrm{L}$ in methanol) aliquot of I. scheffleri subsp. keniensis EO was mixed with 0.45 $\mathrm{mL}$ of DI and $2.5 \mathrm{~mL}$ of $0.2 \mathrm{~N}$ Folin-Ciocalteu reagent. After $5 \mathrm{~min}, 2 \mathrm{~mL}$ of saturated sodium carbonate $(75 \mathrm{~g} / \mathrm{L})$ was added. The solution was incubated for $90 \mathrm{~min}$ at $30{ }^{\circ} \mathrm{C}$ with intermittent shaking. The absorbance was measured at $765 \mathrm{~nm}$ after dilution (at 3 parts sample to 57 parts DI water). A standard curve was established for the assay using gallic acid in $80 \%$ methanol. The same procedure was repeated for all the standard gallic acid solutions (0, 50, 100, 150, 200 and $250 \mathrm{mg} / 25 \mathrm{~mL}$ solutions of gallic acid in $80 \%$ methanol) and a standard curve equation was found:

Absorbance $=0.0002 \times$ gallic acid $(\mathrm{mg})+0.0035$

[Eqn 3]

The total phenolic content of the extract as gallic acid equivalents were determined by entering the absorbance value of the sample reaction into the above calibrated equation to find $\mathrm{mg}$ gallic acid equivalents. This was further used to calculate $\mathrm{mg}$ gallic acid equivalents per $\mathrm{mL}$ of the oil. All tests were carried out in triplicate and the results were averaged, and phenolic contents as gallic acid equivalents were reported as a means of triplicate determinations. 


\section{Antimicrobial assay methodology}

\section{Antimicrobial assay test organisms}

The disk diffusion method as described by Korir et al. (2012) and Tepee, Akpulat and Sokmen (2011) was used to evaluate the antimicrobial activity of EO obtained from the leaves of I. scheffleri subsp. keniensis. The following microorganisms were used as test organisms to represent several major groups: S. aureus (American Type Culture Collection [ATCC] 25923), a facultative anaerobic Gram-positive coccal bacterium frequently found as part of the normal skin flora on the skin and nasal passages, B. subtilis (ATCC 6633), a Gram-positive obligate aerobe commonly found in soil, E. coli (ATCC 25922), a Gram-negative, rod-shaped bacterium commonly found in the lower intestine of endotherms, P. aeruginosa (ATCC 2785), a Gram-negative, aerobic rodshaped bacterium and C. albicans (ATCC 90028), a diploid fungus that grows both as yeast and filamentous cells.

All the bacteria were obtained from the Department of Botany at JKUAT, Juja, Kenya and standard isolates were used. The bacteria were maintained at $4{ }^{\circ} \mathrm{C}$ on nutrient agar plates. Mueller-Hinton agar was prepared under sterile conditions as per manufactures instructions. Base plates were prepared by pouring $10 \mathrm{~mL}$ of the prepared sterilised Mueller-Hinton agar cooled to $45^{\circ} \mathrm{C}$ into sterile Petri dishes and allowed to solidify. About $15 \mathrm{~mL}$ of Molten Mueller-Hinton agar kept at $45^{\circ} \mathrm{C}$ was inoculated with each of the broth culture. The turbidity was then adjusted to equal the turbidity of the 0.5 McFarland standard giving a final inoculum of $1.5 \times 10^{8}$ colony forming units (CFU) $/ \mathrm{mL}$ of the test bacterial suspension of the medium and poured over the base plates forming a homogenous top layer. Filter paper discs (Whatman no. 3,6 mm diameter) were sterilised by autoclaving. I. scheffleri subsp. keniensis EOs present in vials were re-dissolved in $10 \%$ dimethyl sulfoxide (DMSO). About $10 \mu \mathrm{L}$ of the Ixora extract was applied per filter paper disc. The discs were air-dried and placed onto the seeded top layer of the Mueller-Hinton agar plates. Air-dried discs saturated with 10\% DMSO were used as negative controls. Filter paper discs loaded with $5 \mathrm{mg}$ of Gentamycin in $10 \%$ DMSO were used as positive controls. The plates were evaluated after incubation at $37{ }^{\circ} \mathrm{C}$ for $24 \mathrm{~h}$ after which the zones of inhibition were measured using Vernier calipers. The size of the inhibition zone in $(\mathrm{mm})$ produced by the EO was recorded and considered to express the antibacterial activity. In vitro antifungal activity was performed on C. albicans as described for bacterial assays except that Sabourands dextrose Chloramphenicol agar was used to test antifungal bioactivity and incubation was conducted at $25^{\circ} \mathrm{C}$ for $120 \mathrm{~h}$ for yeasts and filamentous fungi. Each of these assays was analysed in triplicate. The results of the disk diffusion test were 'qualitative', in that a category of susceptibility (i.e., susceptible, intermediate or resistant) is derived from the test rather than an minimun inhibition concentration (MIC).

\section{Ethical considerations}

This article followed all ethical standards for research without direct contact with human or animal subjects.

\section{Results and discussion \\ Chemical composition of the essential oils and the phenolic compounds}

The hydrodistillation of the I. scheffleri subsp. keniensis leaves delivers a light yellowish oil with a yield of $0.77 \%$ (weight by weight $[w / w])$. Gas chromatography mass spectrometry analysis of the EO revealed that a total of 29 compounds have been identified representing around $90 \%$ of the total oil. The identified compounds have been summarised in Table 1 . The major chemical constituents $(>5 \%)$ of the oil were: 2,3-dihydroxybenzaldehyde (4.5\%), 6-methoxycoumaran3-one (1.3\%), ethyl 7,7-diformylhepta-2,4,6-trienoate (3.0\%), 3-O-methyl-d-glucose, (5.3\%), 7-quinolinol (2.0\%), n-butyric acid 2-ethylhexyl ester (7.2\%), benzofuran-2carboxaldehyde $(22.0 \%), 2,3,4$-trihydroxybenzaldehyde $(10.3 \%)$, hydroquinone (7.5\%), 2,6-dimethyl-1,7-Octadien-3ol (2.1\%), 2,3-dihydrobenzofuran (1.0\%) and 1,2-benzenediol (5.5\%), 2,3-dihydroxybenzaldehyde (4.5\%).

Clearly, the oil is rich in phenolic compounds and as such the obvious next step was to test the antioxidant properties of the oil.

\section{Antioxidant activity}

Figure 3 shows a graph of the DPPH scavenging activities of increasing amounts of I. scheffleri subsp. keniensis EO and ascorbic acid solution expressed as a percentage.

TABLE 1: Essential oil composition of Ixora scheffleri subsp. keniensis.

\begin{tabular}{|c|c|c|c|}
\hline Compound & Area $(\%)$ & $\mathbf{R I}$ & Method of identification \\
\hline Methyl-cyclopentane & 1.4 & - & RI, MS \\
\hline 1-Hydroxy-2-propanone $\dagger$ & 1.4 & - & RI, MS \\
\hline 2-Propanone, 1,3-dihydroxy- & 0.4 & - & $\mathrm{RI}, \mathrm{MS}$ \\
\hline Pentanol, 5-amino- & 0.1 & - & $\mathrm{RI}, \mathrm{MS}$ \\
\hline 2-Cyclopenten-1-one, 2-hydroxy- & 0.2 & - & $\mathrm{RI}, \mathrm{MS}$ \\
\hline Carbamic acid, phenyl ester & 0.7 & - & $\mathrm{RI}, \mathrm{MS}$ \\
\hline 2-Hydroxy-gamma-butyrolactone & 0.4 & - & $\mathrm{RI}, \mathrm{MS}$ \\
\hline v-Guanidinobutyric acid & 0.4 & - & $\mathrm{RI}, \mathrm{MS}$ \\
\hline Cyclopropyl carbinol & 0.2 & - & $\mathrm{RI}, \mathrm{MS}$ \\
\hline 2-Phenylethanol & 0.7 & - & $\mathrm{RI}, \mathrm{MS}$ \\
\hline 2,3-Dihydroxybenzaldehyde $\dagger$ & 4.5 & 839.2 & $\mathrm{RI}, \mathrm{MS}$ \\
\hline 2,6-Dimethyl-3,7-Octadiene-2,6-diol & 0.2 & 866.2 & $\mathrm{RI}, \mathrm{MS}$ \\
\hline 1,2-Benzenediol $\dagger$ & 5.5 & 879.9 & $\mathrm{RI}, \mathrm{MS}$ \\
\hline 2,3-Dihydro-benzofuran & 1.0 & 897.1 & $\mathrm{RI}, \mathrm{MS}$ \\
\hline Hydroquinone $\dagger$ & 7.5 & 952.4 & $\mathrm{RI}, \mathrm{MS}$ \\
\hline 2,6-Dimethyl-1,7-Octadien-3-ol† & 2.1 & 1005.9 & $\mathrm{RI}, \mathrm{MS}$ \\
\hline 2,6-Dimethyl-2,7-Octadiene-1,6-diol & 0.4 & 1012.7 & $\mathrm{RI}, \mathrm{MS}$ \\
\hline 2,3,4-Trihydroxybenzaldehyde $\dagger$ & 10.3 & 1042.1 & $\mathrm{RI}, \mathrm{MS}$ \\
\hline 3-Hydroxy-5-methoxy-benzenemethanol & 0.6 & 1060.1 & $\mathrm{RI}, \mathrm{MS}$ \\
\hline Benzofuran-2-carboxaldehyde $\dagger$ & 22.0 & 1114.5 & $\mathrm{RI}, \mathrm{MS}$ \\
\hline 1,6-Octadiene, 3-ethoxy-3,7-dimethyl- $\dagger$ & 1.9 & 1168.5 & $\mathrm{RI}, \mathrm{MS}$ \\
\hline$n$-Butyric acid 2-ethylhexyl ester $\dagger$ & 7.2 & 1286.8 & $\mathrm{RI}, \mathrm{MS}$ \\
\hline 7-Quinolinol† & 2.0 & 1302.7 & $\mathrm{RI}, \mathrm{MS}$ \\
\hline d-Mannose & 1.5 & 1343.4 & $\mathrm{RI}, \mathrm{MS}$ \\
\hline 3-O-Methyl-d-glucose $\dagger$ & 5.3 & 1388.6 & $\mathrm{RI}, \mathrm{MS}$ \\
\hline $\begin{array}{l}\text { Ethyl 7,7-diformylhepta-2,4,6- } \\
\text { trienoate } \dagger\end{array}$ & 3.0 & 1465.0 & RI, MS \\
\hline 6-Methoxycoumaran-3-one $\dagger$ & 1.3 & 1484.9 & $\mathrm{RI}, \mathrm{MS}$ \\
\hline
\end{tabular}

$\mathrm{RI}$, retention index; MS, mass spectrum

$\dagger$, Major components that may be significant in inducing antioxidant activity. 
The $\beta$-carotene-linoleate method is a hydrogen atom transfer assay where antioxidant capacity is determined by measuring the inhibition of the linoleic acid oxidation products especially the conjugated diene hydroperoxides from attacking the $\beta$-carotene, resulting in the bleaching of its characteristic yellow colour (Kulisic et al. 2004; Tepe et al. 2011; Terpinc et al. 2009). The DPPH method is not specific and applies to the overall antioxidant capacity of the sample and as such provides a good measure of the functional properties of the oil. The odd electron in the $\mathrm{DPPH}$ free radical gives a strong absorption maximum at $517 \mathrm{~nm}$ and is purple in colour. After reduction by an antioxidant, the colour turns from purple to yellow as the molar absorptivity of the DPPH radical at $517 \mathrm{~nm}$ reduces from 9660 to 1640 when the odd electron of the DPPH radical becomes paired with a hydrogen from a free radical scavenging antioxidant to form the reduced DPPH-H (Molyneux 2004). The reaction schematic is shown in Figure 2. The resulting decolorisation is stoichiometric with respect to the number of electrons captured.

A DPPH inhibition activity of $16.6 \mu \mathrm{g} / \mathrm{mL}$ ascorbic acid was determined to be $96 \%$ with no increase in inhibition activity with an increase in concentration. For the EO there was a gradual increase between $0 \mu \mathrm{g} / \mathrm{mL}$ and $30 \mu \mathrm{g} / \mathrm{mL}$ in inhibition activity reaching a maximum of about $92 \%$ with

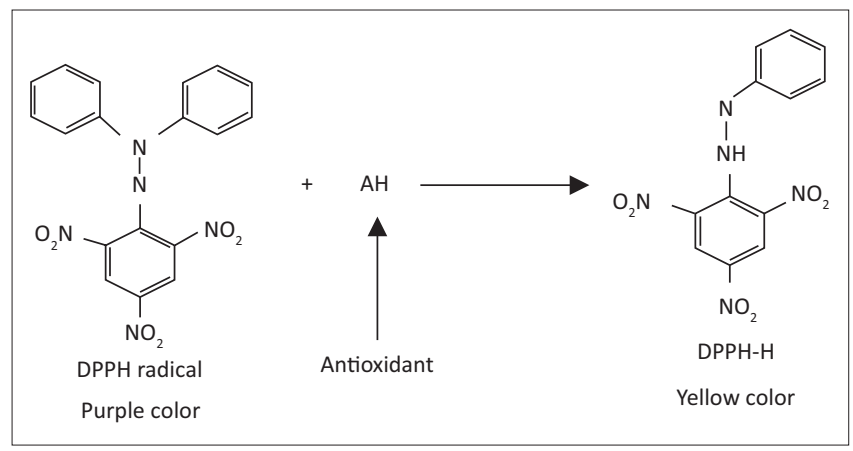

$\mathrm{N}$, Nitrogen; $\mathrm{O}, \mathrm{N}, 5-\{[(2-\{[$ bis(4-methoxyphenyl)methyl]carbamoyl\}benzyl)(prop-2-en-1-yl) amino]methyl\}-1,3-benzodioxole-4-carboxylic acid; $\mathrm{NO}_{2}$, Nitrogen dioxide; $\mathrm{AH}$, Antioxidant DPPH, 1,1-diphenyl-2-picrylhydrazyl; DPPH-H, 1-diphenyl-2-picrylhydrazyl-Hydrogen.

FIGURE 2: Hydrogen atom transfer reaction schematic of the 2,2-diphenyl-1picrylhydrazyl free radical with an antioxidant.

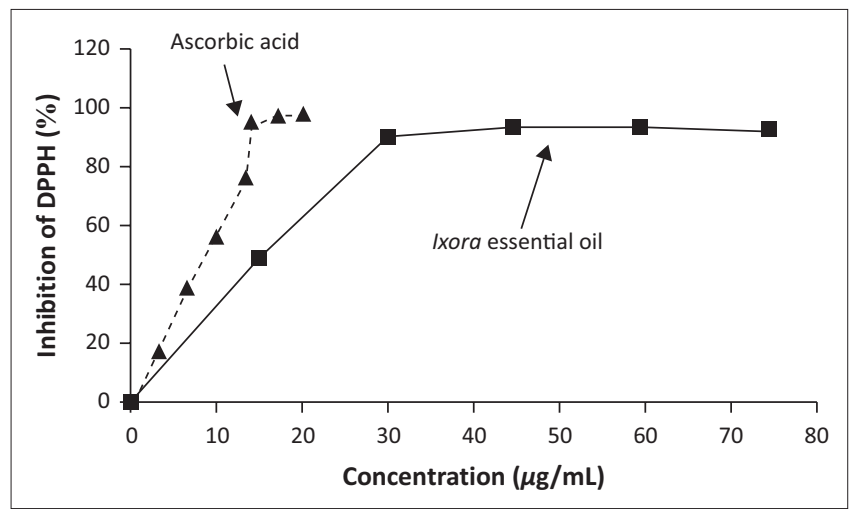

DPPH, 1,1-diphenyl-2-picrylhydrazyl.

FIGURE 3: Comparison of 2,2-diphenyl-1-picrylhydrazyl radical scavenging activities of Ixora scheffleri subsp. keniensis essential oil and ascorbic acid at different concentrations.
TABLE 2: Antimicrobial activity of essential oil of $10-\mu \mathrm{L}$ of Ixora scheffleri subsp. keniensis essential oil using the agar diffusion method.

\begin{tabular}{lcl}
\hline Microbial strain & $\begin{array}{c}\text { Mean diameter zones of } \\
\text { inhibition }(\mathrm{mm})\end{array}$ & Susceptibility \\
\hline Bacillus subtilis & $6.0 \pm 0.0$ & Resistant \\
Escherichia coli & $10.5 \pm 0.3$ & Susceptible \\
Pseudomonas aeruginosa & $6.0 \pm 0.0$ & Resistant \\
Candida albicans & $6.7 \pm 0.0$ & Intermediate \\
Staphylococcus aureus & $6.0 \pm 0.0$ & Resistant \\
\hline
\end{tabular}

the addition of $30 \mu \mathrm{g} / \mathrm{mL} \mathrm{EO}$, beyond which the inhibition did not increase with concentration. The $\mathrm{IC}_{50}$ for I. scheffleri subsp. keniensis EO was determined to be $15.1 \mu \mathrm{g} / \mathrm{mL}$ $\pm 0.1 \mu \mathrm{g} / \mathrm{mL}$ while that of ascorbic acid was $8.5 \mu \mathrm{g} / \mathrm{mL} \pm$ $0.2 \mu \mathrm{g} / \mathrm{mL}$, as was reported by Khalaf et al. (2008). It is notable that $I$. scheffleri subsp. keniensis EO has higher antioxidant activity than commonly used herbs such as Cinnamomum zeylanicum leaves $(53 \mu \mathrm{g} / \mathrm{mL})$, clove buds $(36 \mu \mathrm{g} / \mathrm{mL})$, jasmine absolute $(1297 \mu \mathrm{g} / \mathrm{mL})$ and thyme red $(1563 \mu \mathrm{g} / \mathrm{mL})$ (Wang, Wang \& Yih 2008). Additionally, the $\mathrm{IC}_{50}$ value for green tea was $6.7 \mu \mathrm{g} / \mathrm{mL}$ and for black tea it was $9.7 \mu \mathrm{g} / \mathrm{mL}$ as determined by Khalaf et al. (2008). The same authors determined the $\mathrm{IC}_{50}$ value of the synthetic antioxidant BHT to be $19.8 \mu \mathrm{g} / \mathrm{mL}$. The $\mathrm{IC}_{50}$ values of other common herbs such as peppermint, spearmint and rosemary were determined by Gharib and Teixeira da Silva (2013) to be $59.19 \mu \mathrm{g} / \mathrm{mL}, 63.80 \mu \mathrm{g} / \mathrm{mL}$ and $62.49 \mu \mathrm{g} / \mathrm{mL}$, respectively. It is clearly evident therefore that the antioxidant potency of EO from Ixora leaves is significantly high compared to these common herbs. The RAA\% of I. scheffleri subsp. keniensis EO was found to be $52 \%$ of that of BHT.

The total phenolic content of I. scheffleri subsp. keniensis EO was found to be $91.6 \mu \mathrm{g} \pm 0.5 \mu \mathrm{g}$ of GA/mg. The high content of phenolic compounds that the main active agents that can donate hydrogen to free radicals (scavenging effect) and thus break the chain reaction of lipid oxidation, is clearly indicative of the high antioxidant activity of the Ixora EO.

While it was clearly evident that Ixora EO demonstrated significant antioxidant activity as the three chemical assays tests determined, it was important to evaluate if it could have added benefits of bioactivity. As mentioned in the 'Methods' section, the bioactivity of Ixora EO was screened against several microbial strains and the mean diameter zones of inhibition were determined using the disc diffusion method. The antimicrobial susceptibility test results against the test organisms are summarised in Table 2. From the table, it is evident that Ixora EO had significant activity against $E$. coli with a mean diameter zone inhibition of $10.5 \mathrm{~mm}$. The EO also had some activity against $C$. albicans $(6.7 \mathrm{~mm})$ and no activity $(6.0 \mathrm{~mm})$ against $B$. subtilis, Pseudomonas aeruginosa and $S$. aureus. The diameter of the disc was $6 \mathrm{~mm}$ and so any value above this indicated some degree of inhibition.

\section{Conclusion}

The antioxidant, antibacterial and antifungal activity of EO of I. scheffleri subsp. keniensis found in Central Kenya is 
presented here for the first time and extends knowledge in the range of valuable biological activities and possible roles in therapy associated with this medicinal herb.

Results from both DPPH and $\beta$-carotene linoleic acid assays established that I. scheffleri subsp. keniensis EO possesses antioxidant and radical scavenging potency. However, the EO antioxidant properties were found to be slightly lower compared to the standard antioxidant ascorbic acid. Despite having lower activity compared to standard ascorbic acid, the antioxidant activity of I. scheffleri subsp. keniensis EO was found to be significant for potential applications in the food, cosmetic and pharmaceutical industries and could act as a potential alternative to more toxic synthetic antioxidants. Because of the toxic nature of EOs, further studies on the toxicity and other biological properties of the extract are needed prior to possible applications. Also electrochemical antioxidant activity, another good indicator of the antioxidant nature of the EOs would be a useful study. It is also notable that the EO may be a good source of bioactive compounds especially against microbes such as E. coli (susceptible) and against C. albicans fungi which showed intermittent susceptibility.

\section{Acknowledgements}

Mr Josphat Muthanga of Jomo Kenyatta University of Agriculture and Technology is acknowledged for assisting in extractions. Merrill Singleton, Karl Ayton and Richard Eastwood, who were students of MacEwan University, are acknowledged for assisting in data analysis.

\section{Competing interests}

The authors have declared that no competing interests exist.

\section{Authors' contributions}

P.K.N. collected the plant samples, carried out extractions and was also involved in drafting the manuscript. S.M.M. conducted the data analysis, interpretation and drafting of the manuscript.

\section{Funding information}

This research was funded by the MacEwan University Research Scholarly Activity and the Creative Achievement fund.

\section{Data availability statement}

Data sharing is not applicable to this article as no new data were created or analysed in this study.

\section{Disclaimer}

The views and opinions expressed in this article are those of the authors and do not necessarily reflect the official policy or position of any affiliated agency of the authors.

\section{References}

Akowuah, G.A., Ismail, Z., Norhayati, I. \& Sadikun, A., 2005, 'The effects of different extraction solvents of varying polarities on polyphenols of Orthosiphon stamineus and evaluation of the free radical-scavenging activity', Food Chemistry 93(2), 311-317. https://doi.org/10.1016/j.foodchem.2004. 09.028

Amiri, H., 2014, 'Chemical composition and antioxidant activity of essential oil and methanolic extracts of Ferula microcolea (Boiss.) Boiss (Apiaceae)', International Journal of Food Properties 17(4), 722-730. https://doi.org/10.1080/10942912.20 12.665403

Antolovich, M., Prenzler, P. \& Patsalides, E., 2002, 'Methods for testing antioxidant activity', Analyst 127(1), 183-198.

Antolovich, M., Prenzler, P., Robards, K. \& Ryan, D., 2000, 'Sample preparation in the analysis of phenolic compounds in fruits', Analyst 125(5), 989-1009. https://doi. org/10.1039/b000080i

Barros, L., Cabrita, L., Boas, M.V., Carvalho, A.M. \& Ferreira, I.C.F.R., 2011, 'Chemical, biochemical and electrochemical assays to evaluate phytochemicals and antioxidant activity of wild plants', Food Chemistry 127(4), 1600-1608. https:// doi.org/10.1016/j.foodchem.2011.02.024

Beentje, H.J., Adamson, J. \& Bhanderi, D., 1994, Kenya trees, shrubs and lianas, p. 722 , National Museums of Kenya, Nairobi. ISBN: 9789966986108.

Bridson, D.M., 1988, 'Ixora', in D.M. Bridson \& B. Verdcourt (eds.), Flora of East Tropical Africa, pp. 610-617, Crown Agents Publishing, London.

Derwich, E., Benziane, Z., Boukir, A. \& Benaabidate, L., 2009, 'GC-MS analysis of the leaf essential oil of Mentha rotundifolia, a traditional herbal medicine in Morocco', Chemical Bulletin of Politehnica University of Timisoara 54(68), $85-88$.

Gachathi, F.N., 2007, Kikuyu botanical dictionary: A guide to plant names, uses and cultural values, p. 151, English Press, Kenya.

Gharib, F.A.E.L. \& Teixeira da Silva, J.A., 2013, 'Composition, total phenolic content and antioxidant activity of the essential oil of four lamiaceae herbs', Medicinal and Aromatic Plant Science and Biotechnology 7, 19-27.

Gholivand, M.B., Rahimi-Nasrabadi, M., Batooli, H. \& Ebrahimabadi, A.H., 2010, 'Chemical composition and antioxidant activities of the essential oil and methanol extracts of Psammogeton canescens', Food and Chemical Toxicology 48(1), 24-28. https://doi.org/10.1016/j.fct.2009.09.007

Hatano, T., Kagawa, H., Yasuhara, T. \& Okuda, T., 1988, 'Two New Flavonoids and Other Constituents in Licore Root: Their Relative Astringency and Radical Scavenging Affects', Chemical and Pharmaceutical Bulletin 36(6), 2090-2097. http://dx.doi.org/10.1248/cpb.36.2090

International Union for Conservation of Nature (IUCN), 2004, 2004 IUCN red list of threatened species, viewed 10 January 2018, from www.redlist.org.

Khalaf, N.A., Shakya, A.K., Al-Othman, A., El-Agbar, Z. \& Farah, H., 2008, 'Antioxidant activity of some common plants', Turkish Journal of Biology 32(1), 51-55.

Korir, R., Kimani, C., Gathirwa, J. \& Wambura, M., 2012, 'In-vitro antimicrobial properties of methanol extracts of three medicinal plants from Kilifi District Kenya', African Journal of Health Sciences 20, 4-10.

Kulisic, T., Radonic, A., Katalinic, V. \& Milos, M., 2004, 'Use of different methods for testing antioxidative activity of oregano essential oil', Food Chemistry 85(4), 633-640. https://doi.org/10.1016/j.foodchem.2003.07.024

Mollica, A., Locatelli, M., Macedonio, G., Carradori, S., Sobolev, A.P., De Salvador, R.F. et al., 2016, 'Microwave-assisted extraction, HPLC analysis, and inhibitory effects on carbonic anhydrase I, II, VA, and VII isoforms of 14 blueberry Italian cultivars', Journal of Enzyme Inhibition and Medicinal Chemistry 31(sup 4), 1-6. https://doi. org/10.1080/14756366.2016.1214951

Molyneux, P., 2004, 'The use of the stable free radical diphenylpicrylhydrazyl (DPPH) for estimating antioxidant activity', Songklanakarin Journal of Science and Technology 26(2), 211-219.

Nascimento, G.G., Locatelli, J., Freitas, P.C. \& Silva, G.L., 2000, 'Antibacterial activity of plant extracts and phytochemicals on antibiotic-resistant bacteria', Brazilian Journal of Microbiology 31(4), 247-256. https://doi.org/10.1590/S151783822000000400003

Okoh, O.O., Sadimenko, A.P. \& Afolayan, A.J., 2011, 'Antioxidant activities of Rosmarinus officinalis $\mathrm{L}$. essential oil obtained by hydro-distillation and solvent free microwave extraction', African Journal of Biotechnology 10(20), 4207-4211.

Peschel, W., Sanchez-Rabaneda, F., Diekmann, W., Plescher, A., Gartzia, I., Jiménez, D. et al., 2006, 'An industrial approach in the search of natural antioxidants from vegetable and fruit wastes', Food Chemistry 97(1), 137-150. https://doi. org/10.1016/j.foodchem.2005.03.033

Politeo, O., Jukic, M. \& Milos, M., 2006, 'Chemical composition and antioxidant activity of essential oils of twelve spice plants', Croatica Chemica Acta 79(4), 545-552.

Srivastava, J., Lambert, J. \& Vietmeyer, N., 2005, 'Medicinal plants: An expanding role in from Western India for potential antimicrobial activity', Indian Journal of Pharmacology 37, 406-409.

Taga, M.S., Miller, E.E. \& Pratt, D.E., 1984, 'Chia seeds as a source of natural lipid antioxidants', Journal of the American Oil Chemists' Society 61(5), 928-931. https://doi.org/10.1007/BF02542169

Tepe, B., Akpulat, H.A. \& Sokmen, M., 2011, 'Evaluation of the chemical composition and antioxidant activity of the essential oils of Peucedanum longifolium and $P$. Palimbiooides', Records of Natural Products 5, 108-116. 
Terpinc, P., Bezjak, M. \& Abramovic, H., 2009, 'A kinetic model for evaluation of the antioxidant activity of several rosemary extracts', Food Chemistry 115(2) 740-744. https://doi.org/10.1016/j.foodchem.2008.12.033

Topal, M., Gocer, H., Topal, F., Kalin, P., Köse, L.P., Gülçin, I. et al., 2016, 'Antioxidant, antiradical, and anticholinergic properties of cynarin purified from the Illyrian thistle (Onopordum illyricum L.)', Journal of Enzyme Inhibition and Medicinal Chemistry 31(2), 266-275. https://doi.org/10.3109/14756366.2015.1018244

Ushio-Fukai, M. \& Nakamura, Y., 2008, 'Reactive oxygen species and angiogenesis: NADPH oxidase as target for cancer therapy', Cancer Letters 266(1), 37-52. https://doi.org/10.1016/j.canlet.2008.02.044
Vemin, G., Lageot, C. \& Parkanyi, C., 1998, 'GC-MS (El, PCl, NCl, SIM, ITMS) data bank analysis of flavors and fragrances, Kovats indices', Developments in Food Science 39, 245-301. https://doi.org/10.1016/S0167-4501(98) 80012-5

Wang, H.F., Wang, Y.K. \& Yih, K.H., 2008, 'DPPH free-radical scavenging ability, total phenolic content, and chemical composition analysis of forty-five kinds of essential oils', Journal of Cosmetic Science 59(6), 509-522. https://doi. org/10.1111/j.1468-2494.2009.00531_5.x

Whitney, H.A.K., 1989 , Book Review: British pharmacopoeia 1988, Sage, 23(5), 433. https://doi.org/10.1177/106002808902300525 